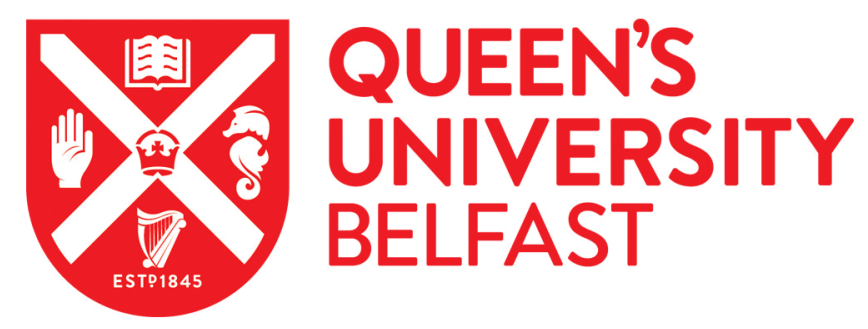

\title{
Sports-Related Concussion (SRC) in Road Cycling - the Roadside head injury assessment (RIDE) for Elite Road Cycling
}

Elliott, J., Jones, N., Loosemore , M., Kemp, S., \& Heron, N. (2019). Sports-Related Concussion (SRC) in Road Cycling - the Roadslde head injury assessment (RIDE) for Elite Road Cycling. British Journal of Sports Medicine. https://doi.org/10.1136/bmjsem-2019-000525

Published in:

British Journal of Sports Medicine

Document Version:

Publisher's PDF, also known as Version of record

Queen's University Belfast - Research Portal:

Link to publication record in Queen's University Belfast Research Portal

Publisher rights

Copyright 2019 the authors.

This is an open access Creative Commons Attribution-NonCommercial License (https://creativecommons.org/licenses/by-nc/4.0/), which permits use, distribution and reproduction for non-commercial purposes, provided the author and source are cited.

\section{General rights}

Copyright for the publications made accessible via the Queen's University Belfast Research Portal is retained by the author(s) and / or other copyright owners and it is a condition of accessing these publications that users recognise and abide by the legal requirements associated with these rights.

Take down policy

The Research Portal is Queen's institutional repository that provides access to Queen's research output. Every effort has been made to ensure that content in the Research Portal does not infringe any person's rights, or applicable UK laws. If you discover content in the Research Portal that you believe breaches copyright or violates any law, please contact openaccess@qub.ac.uk. 
BMJ Open Sport \& Exercise Medicine
Sports-related concussion (SRC) assessment in road cycling: a systematic review and call to action
To cite: Elliott J, Anderson R, Collins S, et al. Sports-related concussion (SRC) assessment in road cycling: a systematic review and call to action. $B M J$ Open Sport \& Exercise Medicine 2019;5:e000525. doi:10.1136/ bmjsem-2019-000525

Accepted 5 March 2019

Check for updates

(C) Author(s) (or their employer(s)) 2019. Re-use permitted under CC BY-NC. No commercial re-use. See rights and permissions. Published by BMJ.

${ }^{1}$ School of Medicine, Dentistry and Biomedical Sciences, Queen's University Belfast, Belfast, UK

${ }^{2}$ Department of Medicine, University of Cambridge, Cambridge, United Kingdom ${ }^{3}$ Department of Medicine and Surgery, Northern Health and Social Care Trust, Coleraine, United Kingdom

${ }^{4}$ General Practice/Centre for Public Health, Queen's University Belfast, Belfast, UK

${ }^{5}$ Department of General Practice, Keele University, Keele, Staffordshire, United Kingdom

\section{Correspondence to} Dr Neil Heron; neilheron@yahoo.co.uk

\section{ABSTRACT}

Background Sports-related concussion (SRC) is a recognised risk in road cycling and can have serious health consequences. Recent high-profile cases of professional road cyclists continuing to participate in races despite suffering obvious SRC have highlighted the difficulties in assessing SRC within road cycling.

Purpose To undertake a systematic review of the literature on SRC assessment in road cycling.

Study design Systematic review.

Methods Literature describing SRC assessment in road cycling was identified by searching MEDLINE, EMBASE, PsycINF0 and Web of Science. Two reviewers independently screened titles and abstracts for eligibility and a qualitative analysis was undertaken of included studies.

Results From 94 studies identified, two were included for review. Gordon et al describe the presentation of a single case of paediatric concussion following a cycling crash. They highlight the utility of SRC evaluation using the Sport Concussion Assessment Tool (SCAT) as well as the importance of a stepwise return-to-play protocol. Greve and Modabber discuss a number of traumatic brain injuries that occurred during the 2011 road cycling season and, as a minimum, call for riders to be withdrawn from competition following loss of consciousness or amnesia. Both studies are at high risk of bias and of low quality. Conclusion Road cycling poses unique challenges for the assessment of SRC. This review illustrates the lack of published evidence to advise effective means of SRC assessment within road cycling. The Union Cycliste Internationale (UCI) regulations advise the use of SCAT-5 for concussion assessment but this tool is impractical, requiring modification for use in road cycling. We would like to call on the UCI to hold a consensus meeting to establish an evidence-based SRC assessment protocol and return-to-riding protocol for road cycling.

\section{INTRODUCTION}

Sports-related concussion (SRC) is a common sports-related injury and a growing global public health concern. ${ }^{1}$ In recent years, great advances have been made globally in the diagnosis and management of the condition in contact sports. However, some sports, particularly road cycling, do not have sport-specific SRC diagnosis and management protocols.

\section{What is already known}

- Epidemiological studies estimate that sports-related concussion (SRC) accounts for $1.3 \%-9.1 \%$ of all road cycling injuries and this incidence is increasing.

- The Sport Concussion Assessment Tool (SCAT-5) can be used for assessment of SRC but requires modification for use in road cycling.

\section{What are the new findings}

- This is the first systematic review of SRC assessment within road cycling.

- Only two articles were identified for the systematic review, highlighting the lack of studies and evidence addressing SRC within road cycling.

- We call on the Union Cycliste Internationale to hold a consensus meeting with road cycling medical teams to develop the SCAT-5 for use in road cycling, including an appropriate return-to-play protocol.

Determining the exact incidence of SRC is difficult as not all concussions are reported and only recently has there been an effort to differentiate the term from other injuries such as mild traumatic brain injury (mTBI). ${ }^{2}$ The Center for Disease Control has released statistics on the incidence of non-fatal TBIs related to sports and recreation activities in the USA. These statistics show that approximately 1.4 million persons are treated for TBIs annually in the USA and, of these, an estimated 207830 are related to sports and recreation. Cycling is reported to account for $40424(19.45 \%)$ of cases, the highest number in any sport. ${ }^{3}$ Furthermore, epidemiological studies estimate that SRC accounts for $1.3 \%-9.1 \%$ of all injuries reported during cycling events $^{4-6}$ including just over $2 \%$ of the injuries reported during the Tour de France after analysing 8 years of injuries between 2010 and $2017,{ }^{7}$ and their incidence is increasing. ${ }^{8}$ Indeed cycling is a very popular sport and form of physical activity, with $12 \%$ of the general adult population in England 
reported to cycle at least once a week and $3.4 \%$ cycling five times a week. ${ }^{9}$

The fifth Concussion Consensus Conference in Berlin (2017) defined SRC as á complex pathophysiological process affecting the brain, induced by traumatic biomechanical forces ${ }^{10}$ and highlighted several clinical features that can be used to suspect SRC in any athlete. Indeed understanding the impact of SRC on athletes is ever increasing. Guidelines regarding graduated returnto-play have been well developed in contact sports such as soccer, rugby and Australian Football League (AFL) and adapted for use in cycling but these are not evidenced based and often do not take into account the unique demands of a sport such as road cycling. Returning to sport too soon after SRC can expose the athlete to increased risk of repeat injury or sustaining a new musculoskeletal injury and prolonged physiological symptoms that may become more severe ${ }^{11-14}$ as well as exposing the other race participants to an increased risk of injury from, for example, the concussed athlete causing an accident due to impaired balance, which is commonly found following SRC. ${ }^{10}$

There are also potential long-term consequences for athletes suffering SRC and there are ongoing studies in this area. Several studies of retired contact and combat sport athletes show increased incidence of depression and cognitive deficit later in life, with an association between cognitive deficit and the number of concussions suffered. Posthumous neuroimaging studies show moderate evidence of changes at both a microscopic and macroscopic level, as well as some evidence of neurochemical and functional changes. ${ }^{15}{ }^{16} \mathrm{In}$ recent years, a number of studies have been conducted with former National Football League (NFL) players, studying the link between concussion and long-term development of Chronic Traumatic Encephalopathy. It is, therefore, important to be able to diagnosis SRC in road cyclists via an agreed road cycling specific SRC assessment procedure and therefore reduce both the potential short-term and long-term consequences to the athlete and their colleagues.

There have recently been some high-profile cases of professional road cyclists with suspected SRC continuing to participate in the race ${ }^{17}$ and road cycling team staff have highlighted the difficulty in managing suspected SRC in fast-paced sports such as road cycling ${ }^{18}$ as well as the often remote nature of medical monitoring for elite road cyclists-with the athlete often being in one country and the medical team in another. These cases and medical issues unique to the professional sport of road cycling have highlighted the lack of a sport-specific SRC assessment protocol in road cycling. Thus, the aim of this study was to undertake a systematic review of the literature on SRC assessment in road cycling. This knowledge base could then help in the development of a specific road cycling SRC protocol, including a return-to-play protocol following an SRC diagnosis.

\section{METHODS}

This systematic review is reported in line with the Preferred Reporting Items for Systematic Reviews and Meta-analyses guidance. ${ }^{19}$ This review focused on any peer-reviewed published articles which described SRC assessment in road cycling. We searched the appropriate medical databases including MEDLINE, EMBASE, PsycINFO and Web of Science. Studies were excluded if they were not relevant to road cycling. Two reviewers independently screened titles and abstracts for eligibility. Figure 1 demonstrates the flow diagram of reviewed and included studies. Due to the lack of available studies in this area, a qualitative analysis was undertaken of included studies.

\section{Search methods for identification of studies}

Detailed search strategies were developed for each electronic database searched with input from a medical librarian to allow identification of studies for inclusion in this review. The terms searched for across the different databases included:

- Concussion.

- Cycling.

- Road cycling.

Searches were carried out using the following databases: MEDLINE, EMBASE, PsycINFO and Web of Science until January 2018. The titles and abstracts of publications from the search strategy were independently screened by two authors. Additional studies were identified from reviewing the reference lists of the retrieved papers through a handsearch. Articles not meeting the inclusion criteria were discarded. A record was kept of all articles excluded at this stage and the reasons for their exclusion. No language restrictions were made although all papers were written in the English language. Data on methodological issues, eligibility criteria, interventions and study design were extracted independently by two review authors. There was no blinding to study author, institution or journal, and a record was kept of each study included in the review.

\section{Assessment of quality and risk of bias}

The Physiotherapy Edidence Database (PEDro) scale ${ }^{20}$ was used to assess the quality of included papers in the review.

\section{RESULTS}

From 94 studies identified, 65 studies were excluded after screening the titles and abstracts. The full texts of 29 articles were reviewed and two studies were included in the review, with two full-text articles being unable to be traced and reviewed. The most common reasons for studies being excluded were that they were not specific to road cycling or to SRC assessment.

The first paper included in the systematic review was by Gordon $e t a l^{11}$ and is a single case report. They describe the presentation of a single case of paediatric concussion following a cycling crash and highlight the utility of 
evaluation for SRC using the Sport Concussion Assessment Tool (SCAT-2 ${ }^{22}$ in the case report) as well as the importance of a stepwise return-to-play protocol. ${ }^{2122}$

The second paper included in the review was by Greve and Modabber ${ }^{23}$ who present an opinion piece discussing the treatment of TBIs using the 2011 road cycling season as an example. As a minimum they call for riders to be withdrawn from competition following loss of consciousness or amnesia. ${ }^{24}$ They argue that sufficient time and adequate facilities for assessment are simply not possible in professional road cycling because time taken to assess for SRC at the side of the road penalises the rider's position and therefore performance in the race. Both these studies are at high risk of bias and generally of low methodology quality.

\section{DISCUSSION}

\section{Overview}

This is the first systematic review of the literature on SRC assessment in road cycling and 94 studies were identified from our search criteria, with two meeting the inclusion criteria and being included in the review. One study was a case report and the other was an opinion piece, with both being at high risk of bias and of low methodological quality. Both studies highlight the importance of a SCAT assessment for managing concussion in cycling and indeed the stepwise return-to-play protocol that it contains. However, there is a lack of available literature regarding SRC assessment and management in road cycling. We, therefore, call on interested clinicians to address this lack of literature and develop a specific road cycling SRC protocol. The first step to address this issue would be a consensus meeting with all relevant parties, including the Union Cycliste Internationale (UCI) and the medical staff of road cycling teams.

\section{Comparison with previous literature}

Athlete safety should be at the core of professional, and indeed recreational sport. 'If in doubt, sit them out'-the mantra of Sport Scotland's Concussion Guidance ${ }^{25}$-has become a widely adopted phrase in collision sports and cycling should seek to be an early adopter of promoting this culture at elite and community levels. The fifth Concussion Consensus Conference in Berlin (2017) ${ }^{10}$ culminated in the development of an updated version of the SCAT $-5 .{ }^{26}$ The tool incorporates elements designed to effectively and efficiently assess an injured athlete's concussion status. It is designed to be used as a sideline assessment. The elements included in SCAT-5 are:

- Symptom score.

- Physical signs score.

- Glasgow Coma Score.

- Balance examination score.

- Coordination score.

- Standardised assessment of concussion (SAC).

- Orientation.

- Immediate memory.

- Concentration.
- Delayed recall.

- Maddock's questions.

The importance of baseline measurements is also being investigated, however, there are obvious benefits to knowing an individual athlete's preinjury performance on certain tasks such as balance examination and elements of the SAC. Additionally, it is advised that an SRC history should form part of their medical record. While the tool is comprehensive, it has a completion time of around 10-15 min, which is impractical for a number of sports, including road cycling. The Berlin Consensus Statement on Concussion in Sport states that 'Adequate facilities should be provided for the appropriate medical assessment both on and off the field for all injured athletes. In some sports, this may require rule changes to allow an appropriate off-field medical assessment to occur without affecting the flow of the game or unduly penalising the injured player's team. ${ }^{, 26}$ Action must be taken to increase adherence to the Berlin Consensus statement within road cycling, particularly in facilitating a 'pitch-side' SRC assessment within competition, which may require rule changes to accommodate this.

\section{What are the Maddock's questions?}

A primary component of the SCAT- 5 immediate assessment is a list of five questions to test the memory of the injured player, known as the Maddock's questions. These questions are:

- 'What venue are we at today?'

- 'Which half is it now?'

- 'Who scored last in this match?'

- 'Which team did you play in your last game?'

- 'Did you team win the last game?'

Despite being described as a 'critical' element of the SCAT-5 assessment, these questions only apply in a team sport setting (eg, football, rugby, basketball). They are not applicable to individual sports such as road cycling. There is a brief note in the SCAT-5 document saying that 'appropriate sport-specific questions may be substituted', but different questions from different doctors in these individual sports may remove the uniformity and efficiency of the assessment in accurately detecting concussion. A suggested alternative for road cycling specific Maddock's questions could be:

1 . What is the name of this race?

2. How many kilometres are there still to go in today's stage?

3. Who is the road captain today for the race?

4. What was your last race?

5 . What is your coach's name?

These questions could be asked through the radio by the team doctor but road cycling specific questions should be further developed with the UCI and medical staff of the road cycling teams.

\section{Previous SRC guidelines in road cycling}

The American Cycling Association ${ }^{27}$ SRC guidelines were 'intended for education of cycling team managers, 
coaches and athletes of the symptoms and management of concussion in athletes but are not a surrogate for evaluations by appropriately trained medical professionals.' They aim to provide a framework for the administrative arm of the team to put in place systems and processes that establish a bottom line of best practice, on which team medical staff can build on. This is largely based on the outdated SCAT-2, which was developed following the third International Conference on Concussion in Sport in Zurich in $2008 .^{22}$ The guidelines provide recommendations for immediate evaluation of a cyclist with suspected SRC and could help provide guidance for road cycling medical teams to adapt with the UCI for use in road cycling events.

\section{SRC guidelines in other sports}

Sports like rugby are played in comparatively closed environments to road cycling, where a multitude of camera angles can be used to follow general play and individual players. These television images can be followed in real time and replayed using innovative approaches like the myplayXplay concussion spotting system used by the Rugby Football Union. ${ }^{28}$ Another issue unique to road cycling compared with other sports is that athletes cannot be easily removed from play without penalising their position within the race and thus their potential result and performance. A solution to this could perhaps be a concussion assessment at the side of the road, akin to the Head Injury Assessment protocol used in rugby, ${ }^{29}$ with the cyclist then 'moto-paced' back into his position within the race if they pass this assessment. Such an approach could be supported by rule changes and technological support provided and enforced by the UCI to allow for a safe space for thorough identification and management at the roadside.$^{30-32}$ Furthermore, central injury databases, as promoted by other authors, ${ }^{7}$ particularly during the three grand tours in professional cycling, would allow road cycling medical teams to better understand the patterns of SRC injuries and therefore to develop methods of reducing SRC within road cycling.

While the UCI cycling regulations discuss multimodal assessment in suspected SRC and the need for immediate withdrawal from competition if SRC is suspected, no internationally agreed assessment protocol for concussion in road cycling has been published. ${ }^{33}$ The UCI regulations advise the use of SCAT- 5 for concussion assessment but this tool requires modifications for use in road cycling, including adapting the return-to-play programme. The UCI along with individual national cycling federations should seize the opportunity to have a consensus meeting to establish an SRC protocol for road cycling, in line with the precedent set in other sports, ${ }^{34}$ helping to ensure safe cycling, from elite road races to recreational cycling. This should lead to the establishment of a cycling specific SCAT that is valid, effective and multilingual to facilitate the global nature of road cycling and the acute nature of SRC assessment. The tool should also consider the role of both medical and non-medical personnel, for example, neutral mechanics, who may be the first responder following a crash and the need for appropriate rule changes and use of technology to facilitate SRC assessment as well as independent evaluation of the fidelity to the programme. ${ }^{35}$

\section{Strengths and limitations}

This is the first systematic review of the literature on SRC in road cycling. This review attempted to identify all studies of potential relevance by developing a comprehensive search strategy and then supporting this through handsearching reference lists of all text articles examined in the review. The authors sought to include all eligible studies regardless of publication language, although all studies were in English.

This systematic review is limited by the few studies available in this expanding and novel area of research: only two met the inclusion criteria. As mentioned previously, some authors have previously grouped SRC into mTBI and we did not search the literature for mTBI. Thus, some articles relevant to SRC in road cycling may have been missed.

\section{CONCLUSION}

This is the first review of its kind to bring together the available evidence of SRC assessment in road cycling, illustrating the lack of studies in this area. Further work, particularly an SRC cycling specific consensus meeting, is required to build on the existing protocols for managing SRC generally in sport and to adapt these to the unique sporting demands of road cycling, facilitating safer participation in road cycling for all.

Contributors All authors contributed to the systematic review, writing drafts of the manuscript and reviewing the final version of the manuscript for publication.

Funding The authors have not declared a specific grant for this research from any funding agency in the public, commercial or not-for-profit sectors.

Competing interests $\mathrm{NH}$ is a team physician within the World Tour of professional cycling and has received research grants from the National Institute of Health Research (NIHR) and British Association of Sport and Exercise Medicine (BASEM).

Patient consent for publication Not required.

Provenance and peer review Not commissioned; externally peer reviewed.

Open access This is an open access article distributed in accordance with the Creative Commons Attribution Non Commercial (CC BY-NC 4.0) license, which permits others to distribute, remix, adapt, build upon this work non-commercially, and license their derivative works on different terms, provided the original work is properly cited, appropriate credit is given, any changes made indicated, and the use is non-commercial. See: http://creativecommons.org/licenses/by-nc/4.0/.

\section{REFERENCES}

1. Bcbs.com. The steep rise in concussion diagnoses in the U.S. | Blue Cross Blue Shield. [online], 2016. Available: https://www.bcbs.com/ the-health-of-america/reports/the-steep-rise-concussion-diagnosesthe-us [Accessed 26 Nov 2018]

2. McCrory P, Meeuwisse W, Johnston K, et al. Consensus statement on Concussion in Sport--the 3rd International Conference on Concussion in Sport held in Zurich, November 2008. J Sci Med Sport 2009;12:340-51.

3. Nonfatal traumatic brain injuries from sports and Recreation Activities - United states, 2001-2005. JAMA 2007;298.

4. Roi GS, Tinti R. Requests for medical assistance during an amateur road cycling race. Accid Anal Prev 2014;73:170-3. 
5. Emond SD, Tayoun P, Bedolla JP, et al. Injuries in a 1-day recreational cycling tour: bike New York. Ann Emerg Med 1999;33:56-61.

6. Decock M, De Wilde L, Vanden Bossche L, et al. Incidence and aetiology of acute injuries during competitive road cycling. $\mathrm{Br} J$ Sports Med 2016;50:669-72.

7. Haeberle HS, Navarro SM, Power EJ, et al. Prevalence and epidemiology of injuries among elite cyclists in the tour de France. Orthop J Sports Med 2018;6.

8. Yanturali S, Canacik O, Karsli E, et al. Injury and illness among athletes during a multi-day elite cycling road race. Phys Sportsmed 2015;43:348-54.

9. Cyclinguk.org. Cycling UK's Cycling Statistics | Cycling UK. [online], 2018. Available: https://www.cyclinguk.org/resources/cycling-ukcycling-statistics [Accessed 26 Nov 2018].

10. McCrory P, Meeuwisse W, Dvorak J, et al. Consensus statement on concussion in sport-the $5^{\text {th }}$ international conference on concussion in sport held in Berlin, October 2016. Br J Sports Med 2017;12.

11. Guskiewicz KM, McCrea M, Marshall SW, et al. Cumulative effects associated with recurrent concussion in collegiate football players. JAMA 2003;290.

12. McKee AC, Stern RA, Nowinski CJ, et al. The spectrum of disease in chronic traumatic encephalopathy. Brain 2013;136:43-64.

13. Prins ML, Alexander D, Giza CC, et al. Repeated mild traumatic brain injury: mechanisms of cerebral vulnerability. J Neurotrauma 2013;30:30-8.

14. Cross M, Kemp S, Smith A, et al. Professional Rugby Union players have a $60 \%$ greater risk of time loss injury after concussion: a 2 -season prospective study of clinical outcomes. Br J Sports Med 2016;50:926-31.

15. Hampshire A, MacDonald A, Owen AM. Hypoconnectivity and hyperfrontality in retired American football players. Sci Rep 2013;3.

16. Ford JH, Giovanello KS, Guskiewicz KM. Episodic memory in former professional football players with a history of concussion: an event-related functional neuroimaging study. J Neurotrauma 2013;30:1683-701.

17. Hutchinson J. California bleeding. shocking moment $50 \mathrm{mph}$ cyclist crashes out of tour of California.then is nearly mowed down by rivals. The Sun2017.

18. Beaudin M. The inside story of how Cannondale reacted to Toms Skujins' tour of California crash. Bicycling 2017

19. Moher D, Liberati A, Tetzlaff J, et al. Preferred reporting items for systematic reviews and meta-analyses: the PRISMA statement. $J$ Clin Epidemiol 2009;62:1006-12. 10.

20. Maher CG, Sherrington C, Herbert RD, et al. Reliability of the PEDro scale for rating quality of randomized controlled trials. Phys Ther 2003;83:713-21.

21. Gordon K, Do MT, Thompson W, et al. A 'knock on the noggin'. Paediatr Child Health 2013;18.
22. McCrory P, Meeuwisse W, Johnston K, et al. Consensus statement on concussion in sport - the Third International Conference on Concussion in Sport held in Zurich, November 2008. Phys Sportsmed 2009;37:141-59.

23. Greve MW, Modabber MR. An epidemic of traumatic brain injury in professional cycling: a call to action. Clin J Sport Med 2012;22:81-2.

24. MR, G. An epidemic of traumatic brain injury in professional cycling: a call to action, 2012. PubMed - NCBI. [online] Ncbi.nlm.nih.gov. Available: https://www.ncbi.nlm.nih.gov/pubmed/2238834

25. If in doubt, sit them out. Scottish Sports Concussion Guidance: grassroots sport and general public. [online] Sport Scotland, 2018. Available: https://sportscotland.org.uk/media-imported/1534421/ scottish-sports-concussion-guidance.pdf [Accessed 26 Nov 2018]

26. Sport concussion assessment tool - 5th edition. $\mathrm{Br} J$ Sports Med 2017;51:851-8.

27. Abramson A. Concussions in Cyclists for Team Managers and Coaches. [online], 2012. Available: https://www.usacycling.org/getinvolved/support-role/coaches/resources/concussion-management [Accessed 17 Nov 2018].

28. McCrory P, Meeuwisse W, Dvořák J, et al. Consensus statement on concussion in sport-the 5th International Conference on concussion in sport held in Berlin, October 2016. Br J Sport Med 2017;51:838-47.

29. Abramson A. Concussions in cyclists for team managers and coaches. USA Cycling.

30. Rugby P. Concussion management boosted by ground-breaking new system. [online], 2018. Available: https://www.premiershiprugby. com/news/concussion-management-boosted-ground-breakingnew-system/ [Accessed 26 Nov 2018].

31. Fuller GW, Kemp SPT, Decq P. The International rugby board (IRB) pitch side concussion assessment trial: a pilot test accuracy study. Br J Sports Med 2015;49:529-35.

32. Patricios JS, Ardern CL, Hislop MD et al. Implementation of The 2017 Berlin concussion in sport group consensus statement in contact and collision sports: a joint position statement from 11 national and international sports organisations. Br J Sports Med 2018;52:635-41.

33. Echemendia RJ, Meeuwisse W, McCrory P, et al. The sport concussion assessment tool 5th edition (SCAT5): background and rationale. Br J Sport Med 2017;51:848-50.

34. Medicineofcycling.com. Medicine of Cycling CME Medical Conference and Sports Med Organization @MedOfCycling. [online] 2018. Available: http://www.medicineofcycling.com/guidelines [Accessed 26 Nov 2018].

35. Rulesand Regulations. [online] UCI, 2018. Available: http://www. uci.ch/mm/Document/News/Rulesandregulation/16/26/69/13-SEC20150101-E_English.pdf [Accessed 26 Nov 2018]. 